Research Article

\title{
Hypotensive and Antihypertensive Properties and Safety for Use of Annona muricata and Persea americana and Their Combination Products
}

\author{
Authentia Sokpe $\mathbb{D D}^{1}{ }^{1}$ Merlin L. K. Mensah $\mathbb{D}^{2},{ }^{2}$ George A. Koffuor ${ }^{\mathbb{D}},{ }^{3}$ \\ Kwesi P. Thomford $\left(\mathbb{D},{ }^{4}\right.$ Richmond Arthur $\mathbb{D}^{3}{ }^{3}$ Yakubu Jibira $\mathbb{D D}^{3}$ Michael K. Baah $\mathbb{D}^{2}{ }^{2}$ \\ Bright Adedi, ${ }^{5}$ and Hope Y. Agbemenyah ${ }^{6}{ }^{6}$
}

${ }^{1}$ Department of Pharmacognosy, Faculty of Pharmacy and Pharmaceutical Sciences, KNUST, Kumasi, Ghana

${ }^{2}$ Department of Herbal Medicine, Faculty of Pharmacy and Pharmaceutical Sciences, KNUST, Kumasi, Ghana

${ }^{3}$ Department of Pharmacology, Faculty of Pharmacy and Pharmaceutical Sciences, KNUST, Kumasi, Ghana

${ }^{4}$ Department of Pharmacognosy and Herbal Medicine, University of Cape Coast, Cape Coast, Ghana

${ }^{5}$ Department of Pharmacology and Toxicology, Centre for Plant Medicine Research, Mampong-Akuapem, Ghana

${ }^{6}$ Department of Anatomy and Physiology, University of Health and Allied Sciences, Ho, Ghana

Correspondence should be addressed to George A. Koffuor; gkoffuor@yahoo.com

Received 15 August 2020; Revised 22 October 2020; Accepted 23 November 2020; Published 10 December 2020

Academic Editor: Benoit Banga N’guessan

Copyright (c) 2020 Authentia Sokpe et al. This is an open access article distributed under the Creative Commons Attribution License, which permits unrestricted use, distribution, and reproduction in any medium, provided the original work is properly cited.

\begin{abstract}
Introduction. In the management of hypertension (a cardiovascular disease and the leading metabolic risk factor in noncommunicable diseases) with herbal medicines, efficacy and safety are of uttermost concern. This study sought to establish hypotensive, antihypertensive, drug interaction, and safety for use of the aqueous leaf extracts of Annona muricata (AME), Persea americana (PAE), or their combination products (CAPE). Methodology. Systolic and diastolic blood pressure (SBP and DBP), mean arterial blood pressure (MAP), and heart rate (HR) were measured in normotensive Sprague-Dawley rats treated with 50-150 mg/kg of AME, PAE, or CAPE to establish a hypotensive effect. "Combination index" was calculated to establish interaction between AME and PAE. The antihypertensive effect of CAPE was established by measuring SBP, DBP, MAP, and HR in ethanol-sucrose- and epinephrine-induced hypertension. Full blood count, liver and kidney function tests, and urinalysis were determined in ethanol/sucrose-induced hypertension to establish safety for use. Results. AME, PAE, and CAPE significantly $(p \leq 0.001)$ decreased BP in both normotensive and hypertensive animals. Effects of CAPE 1, CAPE 2, and CAPE 3 were synergistic (combination indices of $0.65 \pm 0.07,0.76 \pm 0.09$, and $0.87 \pm 0.07$, respectively). There was a significant decrease $(p \leq 0.01-0.001)$ in SBP and MAP with $100 \mathrm{mg} / \mathrm{kg}$ CAPE 1 and $75 \mathrm{mg} / \mathrm{kg}$ CAPE 2 treatment in hypertension as well as with nifedipine $(p \leq 0.001)$ treatment. Epinephrine-induced hypertension in anesthetized cats was significantly and dose-dependently inhibited $(p<0.05-0.001)$ by $25-100 \mathrm{mg} / \mathrm{ml} \mathrm{CAPE} 1$ and $37.5-75 \mathrm{mg} / \mathrm{ml} \mathrm{CAPE} 2$. CAPE administration had no deleterious effect $(p>0.05)$ on full blood count, liver and kidney function, and urine composition in hypertensive rats. Conclusion. The aqueous leaf extracts of Annona muricata, Persea americana, and their combination products possess antihypertensive properties, with combination products showing synergism and safety with use.
\end{abstract}

\section{Introduction}

Hypertension is a public health issue, a major contributor to cardiovascular diseases, and the leading metabolic risk factor in noncommunicable diseases. Data from the World Health
Organization [1] revealed that 1.13 billion adults were affected by hypertension in 2015. Despite advances in the field of hypertension management, this figure is estimated to rise to over 1.5 billion adults by 2025 [2,3]. In the provision of antihypertensive drugs, pharmaceutical industries have 
made giant strides in the development of novel synthetic medicines like thiazide diuretics, angiotensin-converting enzyme inhibitors (ACEI), angiotensin receptor blockers (ARBs), beta-blockers, and calcium channel blockers (CCB). However, these synthetic moieties have come with their own challenges $[4,5]$. Many of these medicines though effective in managing hypertension are plagued with side effects for long-term users. Example can be given of the loop diuretics that may produce myalgia, hypokalaemia, and hyperglycaemia [6], the beta-blockers that may come with insomnia and asthmatic symptoms, the CCB that may cause palpitation, headache, constipation, dizziness, and pedal oedema, and the ACEI that may produce the chronic hacking dry cough, lung cancer, and kidney damage in its users $[7,8]$. These factors have become the main drivers influencing the increased usage of herbal medicines by hypertensive patients [9-13].

Despite the popularity and dependency on herbal medicines, there is limited data on their safety and efficacy, and this is a topic of global importance. Many herbal medicines on the market are sold as food supplements due to the lack of preclinical and clinical data to substantiate their claims. More so, the assumption that single herb preparations can fit all is not sustainable since drugs whether botanical, biological, or chemical have inherent limitations if it focuses on only single target. It is important to address polygenic diseases from a syndrome-related metabolic cascade so that holistic management can be effectively achieved. Studies have also shown that plants when combined produce greater therapeutic effect at lower doses than the single herbal preparations [13-15]. This interaction is achieved through pharmacokinetic or pharmacodynamics mechanism.

Persea americana, commonly called avocado pear or alligator pear, is a fruit bearing tree and belongs to the family Lauraceae [16]. In Ghana, it is known as "pea or peya" in Ewe, $\mathrm{Ga}$, Fante, and Twi $[17,18]$. The hypotensive and antihypertensive effects of $P$. americana leaf extract in normotensive and hypertensive Dahl salt-sensitive rats, respectively, have been reported by Ojewole et al. [19] and Owolabi et al. [20]. Annona muricata L. commonly known as soursop, prickly custard, or graviola, a naturally occurring evergreen fruit bearing tree, belongs to the family Annonaceae [21, 22]. In Ghana, the local names include yevu-nyikle or vo (Ewe), apere (Fante), and apre (Twi) [23]. The hypotensive effect of the aqueous leaf extract of A. muricata was reported by Nwokocha et al. [24] in SpragueDawley rats. This study therefore sought to establish activity, a possible drug interaction, and the safety for use of the aqueous leaf extracts of $A$. muricata and $P$. americana and their combination products in the management of hypertension.

\section{Methodology}

2.1. Ethical Consideration. The Committee on Animal Research, Publication and Ethics (CARPE) of the Department of Pharmacology, Faculty of Pharmacy and Pharmaceutical Sciences, KNUST, Ghana, approved this study from an ethical point of view (Ethics Reference Number: FPPS/ PCOL/008/2017).
2.2. Plant Collection and Authentication. The matured leaves of Annona muricata and Persea americana were obtained from Titrinu-Ho (VA-2653-9626) and Kpoeta Ashanti (VH-01475075), respectively, in the Volta Region of Ghana, in November 2017. The plant materials were authenticated by Dr. George Henry Sam of the Department of Herbal Medicine, Faculty of Pharmacy and Pharmaceutical Sciences, KNUST, Kumasi, Ghana. Voucher specimens have been deposited at the Herbarium of the Department, coded Annona muricata (KNUST/ HM1/2019/L009) and Persea americana (KNUST/HM1/2014/ L003 (77)).

\subsection{Preparation of Plant Extracts and Combination Products.} The fresh leaves of $A$. muricata were washed under running tap water to get rid of foreign matter and dried on a wire mesh under the shade at ambient temperature $\left(24-35^{\circ} \mathrm{C}\right)$ for ten (10) days. The dried leaves were milled into a fine powder with a generalpurpose electric blender (Vitamix 5200, Canada). The fresh leaves of $P$. americana were also processed as described above. A weight of $0.7 \mathrm{~kg}$ A. muricata and $2.5 \mathrm{~kg}$ P. americana was infused separately using hot water for 30 minutes and filtered. The filtrates were lyophilized using a vacuum freeze dryer (YK-11850, Taiwan) at the Council for Scientific and Industrial Research, Fumesua, Kumasi, Ghana. The lyophilized powders obtained were labeled as aqueous leaf extract of $A$. muricata (AME) and aqueous leaf extract of $P$. americana (PAE) and kept in an airtight glass container with a desiccator until required for use. A combination product of AME : PAE (CAPE) in the ratios $1: 1,1$ : 2 , and $1: 3$ were prepared and labeled CAPE 1 , CAPE 2 , and CAPE 3, respectively, for use in this study.

2.4. Experimental Animal and Husbandry. Healthy adult Sprague-Dawley rats 12 weeks old weighing $140-240$ g obtained from Centre for Plant Medicine Research (CPMR), Akuapem-Mampong in the Eastern Region of Ghana, were used in this study. Animals were housed in stainless steel cages $(34 \times 47 \times 18 \mathrm{~cm})$ lined with wood shavings. The rats were fed on standard rat chow from Agricare Ltd, Kumasi, Ghana, and water ad libitum. The animals were kept in a well-ventilated room within a temperature range of $25-30^{\circ} \mathrm{C}$ and ambient light and dark cycle of 10-16 hours, respectively.

Healthy adult cats (2 years old, weighing $1.4-2.5 \mathrm{~kg}$ ) obtained from the Animal Facility of Department of Pharmacology, Kwame Nkrumah University of Science and Technology, were used in the epinephrine-induced hypertension experimental model. They were fed on a normal diet (cornmeal mixed with dried fish) and water ad libitum. The animals were kept in a well-ventilated room within a temperature range of $25-30^{\circ} \mathrm{C}$ and ambient light and dark cycle of 10-16 hours, respectively. All animals were treated in accordance with the National Institute of Health Guidelines for the Care and Use of Laboratory Animals (Directive 2010/63/ EU; Animal Care and Use Committee, 1998).

2.5. Hypotensive and Interactive Effects. The hypotensive effects of AME, PAE, and CAPE and possible drug interaction between AME and PAE were investigated. To start up, 
the systolic and diastolic BP and heart rate of grouped (IVII) normotensive rats $(n=6)$ were initially recorded using the noninvasive tail-cuff BP apparatus (UGO Basile 58500, Italy). Groups I-III were then treated with 50,100 , and $150 \mathrm{mg} / \mathrm{kg}$ of AME, respectively, and Groups IV-VI with 50, 100 , and $150 \mathrm{mg} / \mathrm{kg}$ of PAE, respectively, by oral gavage as single doses. Group VII (control) was treated with distilled water and kept under the same experimental conditions. The systolic and diastolic BP and heart rate were then measured at 4,8 , and 24 hours after treatment.

Combinations of AME and PAE (CAPE) in the ratios 1: $1,1: 2$, and $1: 3$ of CAPE $1(100 \mathrm{mg} / \mathrm{kg})$, CAPE $2(150 \mathrm{mg} /$ $\mathrm{kg})$, and CAPE $3(200 \mathrm{mg} / \mathrm{kg})$ were studied as described above. Chou-Talalay method for drug combination (based on the median-effect equation) [25] was employed to establish the "combination index (CI)." For each product combination, the $\mathrm{IC}_{50}$ (experimental), $\mathrm{CI}$, and its associated fraction affected $(\mathrm{Fa})$ were evaluated by a quantitative diagnostic plot (Fa-CI) analysis of the log dose-response curve. The CI was obtained from the following formulas:

$$
\begin{aligned}
\frac{\mathrm{Fa}}{\mathrm{Fu}} & =\left[\frac{D}{D m}\right]^{m}, \\
\log \left[\frac{\mathrm{Fa}}{\mathrm{Fu}}\right] & =m[\log D]-m[\log D m], \\
\mathrm{CI} & =\sum_{j=1}^{n}\left[\frac{D}{D x}\right],
\end{aligned}
$$

where $F a=$ fraction affected, $F u=$ fraction unaffected, $D=$ dose required to produce $\mathrm{Fa}, D m=$ the median dose effect $\left(\mathrm{IC}_{50}\right), m=$ dynamic order (sigmoidicity), and $D x=$ the dose of each drug alone that exerts $X \%$ inhibition. $P$ values for statistical significance were set at 0.05 . Synergism is achieved if $\mathrm{CI}<1$ [25] (Table 1). The mean arterial blood pressure (MAP) was then calculated from the systolic blood pressure (SBP) and diastolic blood pressure (DBP) as follows:

$$
\mathrm{MAP}=\frac{1}{3}(\mathrm{SBP}+2 \mathrm{DBP})
$$

\subsection{Antihypertensive Effect}

2.6.1. Ethanol-Sucrose-Induced Hypertension. The ethanolsucrose-induced hypertension protocol as described by Vasdev et al. [26] and Dzeufiet et al. [27] in adult Sprague-Dawley rats was used in this study, with slight modification. The initial systolic and diastolic blood pressure (SBP and DBP) and heart rate (HR) before induction of hypertension were noted. Hypertension was then induced in the rats by giving $3.2 \mathrm{ml} / \mathrm{kg}$ of $40 \% \mathrm{v} / \mathrm{v}$ ethanol by oral gavage and $10 \% \mathrm{w} / \mathrm{v}$ sucrose solution as drinking water, measuring the SBP and DBP weekly until hypertension (SBP $>140 \mathrm{mmHg}$; DBP $>90 \mathrm{mmHg}$ ) was induced after 6 weeks. Hypertensive animals were then put into 6 groups labeled I-V $(n=6)$ and maintained on ethanol-sucrose. CAPE 1 (50 and $100 \mathrm{mg} / \mathrm{kg}$ ) and CAPE
TABLE 1: Description of drug interactive effects analysed using the combination index method.

\begin{tabular}{lc}
\hline Range of combination index $(\mathrm{CI})$ & Description \\
\hline$<1.0$ & Very strong synergism \\
$0.10-0.30$ & Strong synergism \\
$0.30-0.70$ & Synergism \\
$0.70-0.85$ & Moderate synergism \\
$0.85-0.90$ & Slight synergism \\
$0.90-1.10$ & Nearly additive \\
$1.10-1.20$ & Slight antagonism \\
$1.20-1.45$ & Moderate antagonism \\
$1.45-3.30$ & Antagonism \\
$3.30-10$ & Strong antagonism \\
$>10$ & Very strong antagonism \\
\hline 25$]$ &
\end{tabular}

$2(75 \mathrm{mg} / \mathrm{kg})$ were then administered orally in Groups I-III, respectively. A $0.5 \mathrm{mg} / \mathrm{kg}$ dose of nifedipine (reference drug) was administered to Group IV. Group V (negative control) was treated with normal saline after induction. Treatment of hypertensive rats was done for two (2) weeks with weekly SBP, DBP, and HR measurements.

2.6.2. Epinephrine-Induced Hypertension. The adult cat was anesthetized by intramuscular administration of a mixture of $5 \mathrm{mg} / \mathrm{ml}$ pentobarbitone and $50 \mathrm{mg} / \mathrm{ml} \alpha$-chloralose. The femoral vein and the carotid artery were carefully exposed by shaving off the hair in the area and making an incision in the groin and left side of the neck, respectively. A 20 G cannula was inserted into the femoral vein through which normal saline and the drugs were to be administered. An $18 \mathrm{G}$ cannula was also inserted into the carotid artery which was then connected to a pressure transducer (P23Gb, Statham Instruments, Inc.) through a three-valve catheter. This also served as a passage to introduce heparinized saline to prevent blood coagulation. Care was taken to allow the cat to breathe well. The body temperature was maintained at room temperature $[28,29]$. The initial BP reading was recorded on the pressure transducer. Force of contraction and heart rate were also recorded on kymograph (model 50-822, Harvard Apparatus Ltd., Kent, England). CAPE 1 was administered at concentrations of 15, 25,50 , and $100 \mathrm{mg} / \mathrm{ml}$. In another experiment, CAPE 2 was administered at concentrations of $22.5,37.5$, and $75 \mathrm{mg} / \mathrm{ml}$ to determine the effect on the normotensive cat. At each time, the $\mathrm{BP}$, force of contraction, and heart rate were recorded. To determine the effect of CAPE 1 and CAPE 2 on the hypertensive cat, the products at the same concentrations were coadministered with $20 \mu \mathrm{g} / \mathrm{ml}$ epinephrine. Nifedipine $(75 \mu \mathrm{g} /$ $\mathrm{ml}$ ) was used as the reference antihypertensive drug. Each experiment was done in triplicate [29].

2.6.3. Safety Assessment of CAPE in Hypertension. At the end of treatment in the ethanol-sucrose-induced hypertensive rat model, blood samples from rats in the various treatment groups were obtained from the jugular vein using standard protocols $[30,31]$ into labeled ethylenediaminetetraacetate (EDTA) tubes (Mediplus, Mumbai) for 
hematological profiling and gel separation tubes (Mediplus, Mumbai) for biochemical analysis. Full blood count was done at Noguchi Memorial Institute for Medical Research using an automated haematology analyser (SYSMEX KX$21 \mathrm{~N}$, USA) whilst liver and kidney function tests were performed on the samples at the ChemPath Laboratory, Mampong-Akuapem, using a fully automated chemistry analyser (PENTRA C200, Belgium).

2.6.4. Urine Analysis. Semiquantitative urinalysis was done on freshly obtained urine sample from the urinary bladder of rats using the dipstick (Insight Urinalysis Reagent Strips, Veltlab Ltd.) following the protocol as stated by the manufacturer. Parameters measured include bilirubin, blood, glucose, leucocytes, ketones, nitrites, protein, specific gravity, $\mathrm{pH}$, and urobilinogen.

2.7. Statistical Analysis. Values for parameters measured were expressed as means \pm SEM. Significant differences in treatments were analysed using one-way analysis of variance (ANOVA). Multiple comparisons between groups were done using Dunnett's post hoc test. All statistical analyses were carried out with MS Excel (Microsoft Office, 2016) and GraphPad Prism 6 (GraphPad software, San Diego, California, USA). Values are considered to be statistically significant at $p$ value less than or equal to 0.05 .

\section{Results}

3.1. Hypotensive and Drug Interactive Effects. AME and PAE as well as CAPE 1, CAPE 2, and CAPE 3 dose-dependently and significantly decreased $(p \leq 0.01-0.001)$ SBP, DBP, and MAP in normotensive rats. The effect of AME peaked at the 8 th hour posttreatment and waned towards the 24th hour. PAE had a more sustained effect over the 24-hour period (Figures 1-3). AME and PAE had no effect $(p>0.05)$ on heart rate; however, CAPE 1, CAPE 2, and CAPE 3 caused a significant reduction $(p \leq 0.001)$ of heart rate by the 4 th hour, with the effect waning by the 8 th hour (Table 2). For drug interaction, CAPE 1, CAPE 2, and CAPE 3 caused synergistic effect recording CIs of $0.65 \pm 0.07,0.76 \pm 0.09$, and $0.87 \pm 0.07$, respectively.

\subsection{Antihypertensive Effect}

3.2.1. Ethanol/Sucrose-Induced Model. Administration of ethanol and sucrose solution significantly $(p \leq 0.001)$ induced hypertension in Sprague-Dawley rats by the elevation of SBP, DBP, and MAP compared to that for the normal control group which had minimal variations in the BP readings throughout the experimental period. The elevated SBP, DBP, and MAP in all treatment groups reduced significantly $(p \leq 0.001)$ over the period compared to the negative control. There was no difference $(p>0.05)$ in the measured parameters in week 2 of treatment as compared to the normal control group (Figure 4).
3.2.2. Epinephrine-Induced Hypertension. All concentrations of CAPE $1(15-100 \mathrm{mg} / \mathrm{ml})$ and CAPE $2(22.5-75 \mathrm{mg} /$ $\mathrm{ml})$ caused a significant reduction $(p \leq 0.05-0.001)$ in blood pressure in normotensive cats similar to that caused by $75 \mu \mathrm{g} / \mathrm{ml}$ nifedipine (Figure 5 ).

Epinephrine caused a significant increase $(p \leq 0.001)$ in blood pressure cat, but this effect was dose-dependently and significantly inhibited by all concentrations of CAPE 1 and CAPE 2. Comparison of the inhibitory effect of the combined extract with that of nifedipine revealed that $100 \mathrm{mg} / \mathrm{ml}$ CAPE 1 and $75 \mathrm{mg} / \mathrm{ml} \mathrm{CAPE} 2$ had similar effects (Figure 6).

3.3. Safety Assessment. Safety for use of the combination products of AME and PAE in hypertension was assessed, employing the ethanol/sucrose-induced hypertensive model. Study results indicated no detrimental effect on hematological profile (Table 3). Except for total bilirubin (TBIL) which was significantly reduced $(p \leq 0.001)$ at all dose levels of CAPE 1 and CAPE 2, liver function parameters were not affected $(p>0.05)$, i.e., comparable to the normal control (Table 4). CAPE administration also did not affect kidney function parameters. Urinalysis revealed the reversal of proteinuria caused by the induction of hypertension in the CAPE- and nifedipinetreated rats (Table 5).

\section{Discussion}

This study sought to establish antihypertensive activity and safety for use of aqueous extracts of Annona muricata (AME) and Persea americana (PAE) and their combination products (CAPE); hence, the study involved the measurement of systolic and diastolic blood pressure as well as force and rate of myocardial contraction. Blood pressure is the product of cardiac output and total peripheral resistance. A persistent increase in SBP/DP indicates hypertension [32]. Treatment of normotensive rats with AME, PAE, and CAPE 1, CAPE 2, and CAPE 3 resulted in significantly decreased SBP, DBP, and hence MAP, indicating hypotensive effect. This possibly suggests that the extracts and their combination product contain phytochemicals which possess the ability to possibly cause reduction in cardiac output and/or total peripheral resistance. A decrease in cardiac output results in reduction in the total volume of blood flowing into peripheral blood vessels [33] and hence a reduction in the pressure exerted on the walls of the vessel [33]. Dilatation of the peripheral blood vessel would result in a fall in blood pressure [34] as resistant to blood flow decreases [34]. This will then constitute a fall in blood pressure, i.e., hypotension [34].

Although AME and PAE had no significant effect on heart rate, the combination products caused a significant reduction in heart rate by the 4 th hour, suggesting negative chronotopy and hence a reduction in cardiac output [33] and a fall in BP. This finding could also suggest a possible effect by phytochemicals on the rate of impulse firing by the pacemaker node in the myocardium. The pacemaker node initiates action potential leading to the propagation of 


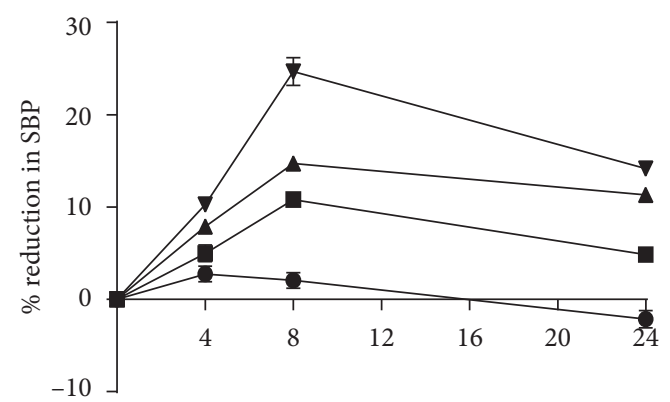

Time (hours)

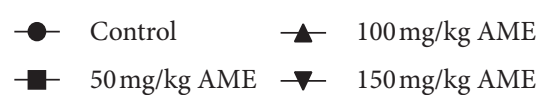

(a)

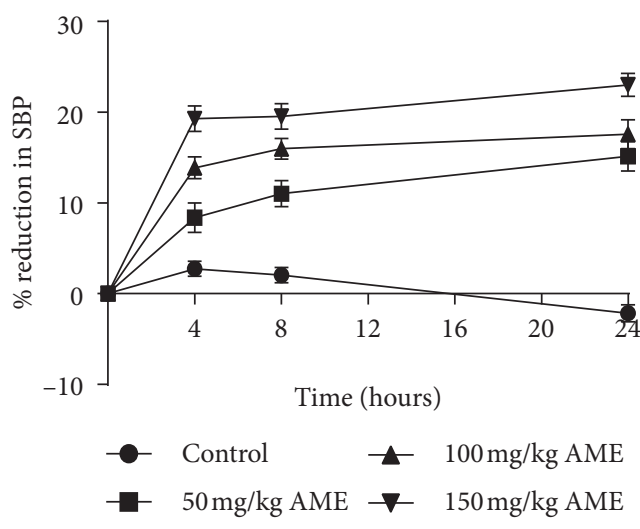

(c)

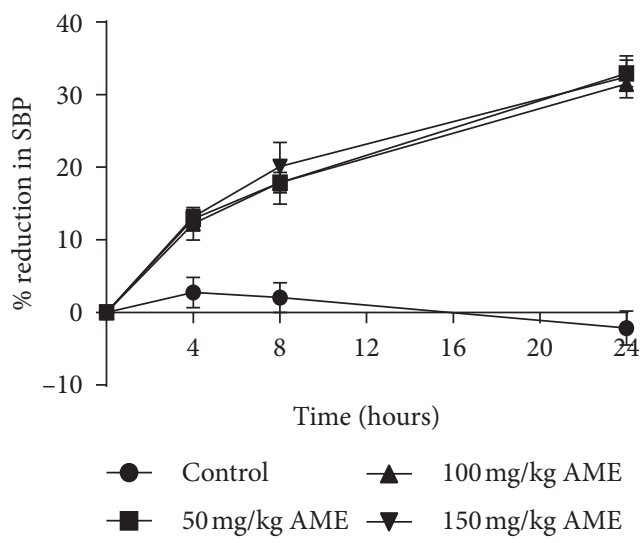

(e)

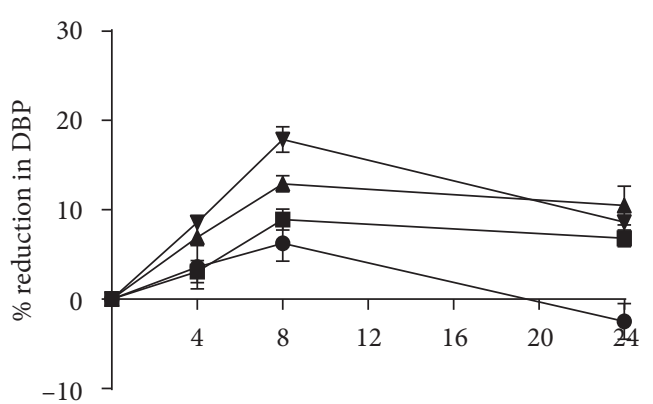

Time (hours)

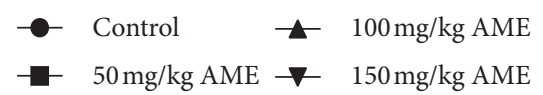

(b)

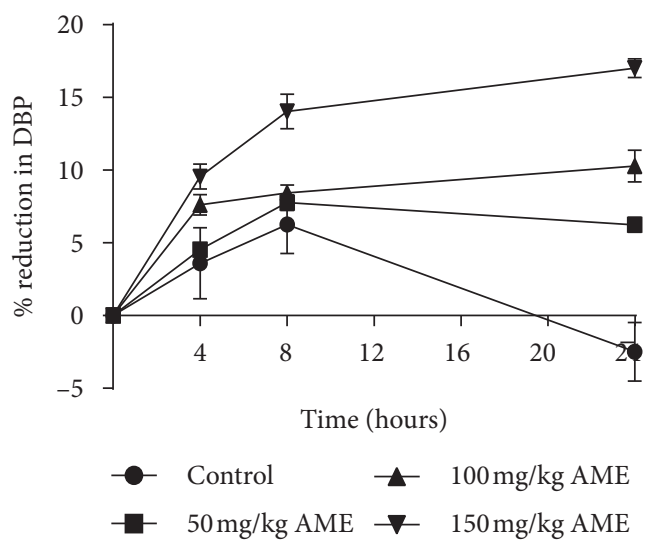

(d)

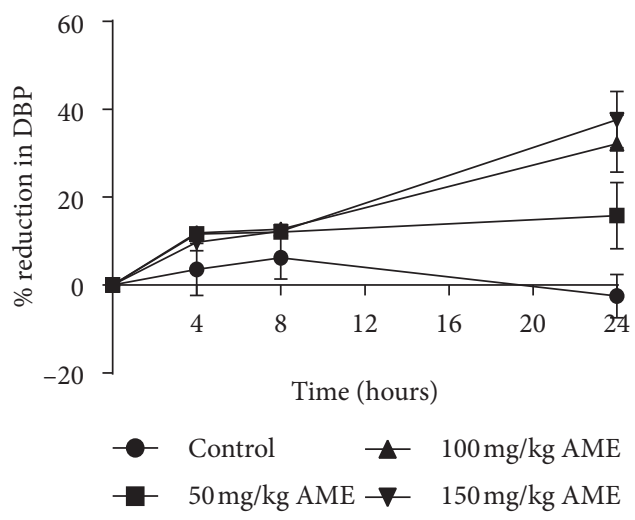

(f)

FIgURE 1: Time course of effect of aqueous extracts of $A$. muricata (a, b) (AME), (c, d) P. americana (PAE) and their combination products $(\mathrm{e}, \mathrm{f})(\mathrm{CAPE})$ on systolic and diastolic BP in normotensive SD rat. Values are plotted as mean \pm SEM $(n=6)$. CAPE 1 , CAPE 2 , and CAPE 3 are combinations of AME:PAE in the ratios $1: 1,1: 2$, and $1: 3$, respectively.

electrical impulse through the electrical conduction system of the heart causing myocardial contraction $[35,36]$ with an overall effect on the blood pressure.

For only the combination products to elicit a significant effect on heart rate, there is reason to suggest possible drug interaction. This interaction was confirmed by the "combination index (CI)" obtained in this study, as mild to severe synergism between AME and PAE as per the Chou-Talalay method for drug combination [25]. Synergy is the desired effect sought to achieve a greater effect than that attained by any drug singly [37]. A synergistic product would therefore be of much preference as an antihypertensive product as its efficacy would be much more enhanced, and toxicity effects reduced (due in part to lower doses of drug administered).

To further confirm the significance of the combination product of AME and PAE in hypertension management, the 


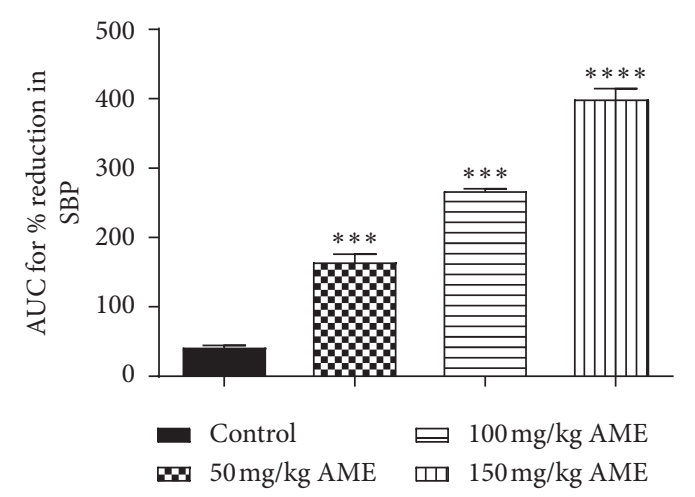

(a)

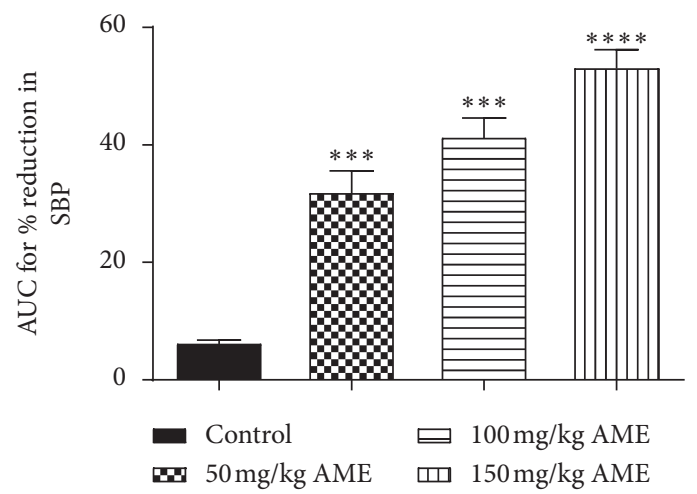

(c)

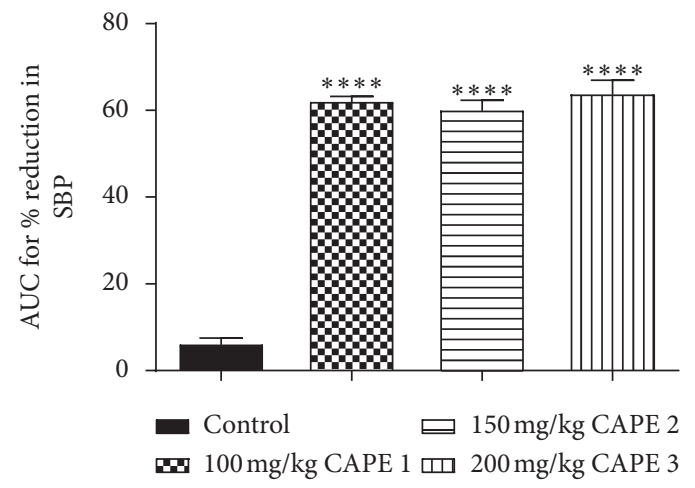

(e)

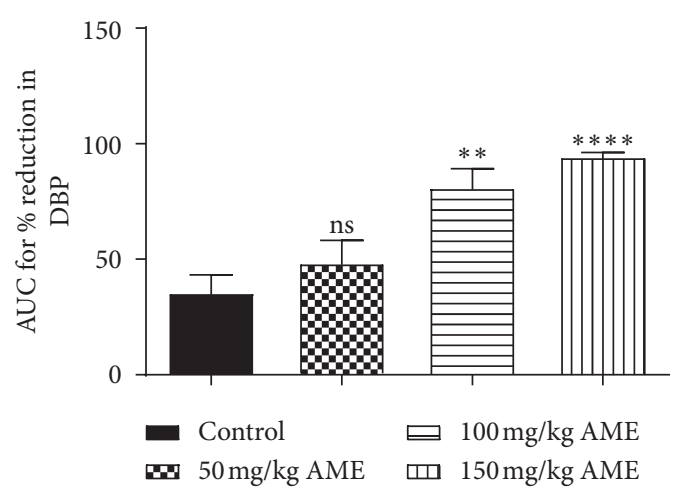

(b)

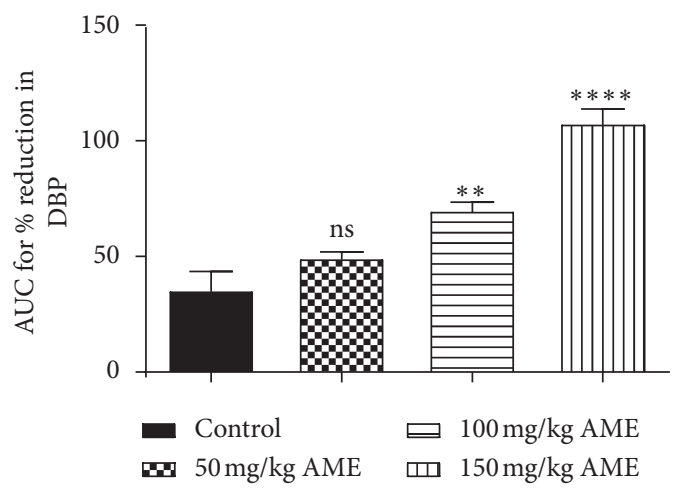

(d)

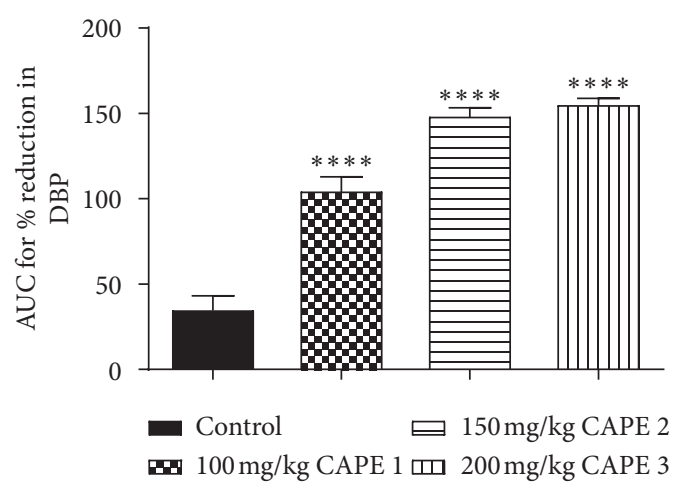

(f)

Figure 2: Plots for area under the curve (AUC) for the time course of effect of (a, b) AME, (c, d) PAE, and (e, f) CAPE on systolic and diastolic BP in normotensive rats. Values are plotted as mean $\pm \operatorname{SEM}(n=6) .{ }^{* * *} p \leq 0.001,{ }^{* *} p \leq 0.01$, ns: $p>0.05$; compared to the control (one-way ANOVA with Dunnett's multiple comparisons post hoc test). CAPE 1, CAPE 2, and CAPE 3 are combinations of AME and PAE in the ratios $1: 1,1: 2$, and $1: 3$, respectively.

ethanol/sucrose-induced [26, 27] and epinephrine-induced hypertensive models $[28,29]$ were used in this study. Administration of ethanol over a significant period of time stimulates the release of endothelin 1 and 2 from vascular endothelium [38] and the release of angiotensin 2 from the renin-angiotensin-aldosterone system (RAAS). These endogenous chemicals are potent vasoconstrictors [39], thus causing vasoconstriction of peripheral vessels [39] and hence an increase in total peripheral resistance $[40,41]$. Furthermore, chronic administration of sucrose stimulates peripheral sympathetic activity and also reduces the baroreceptor reflex with a resultant increase in blood pressure $[39,42]$. The elevated SBP, DBP, and MAP reduced significantly with treatments indicating antihypertensive effect. The combination products of the extracts may have attained their effect by possibly inhibiting the renin-angiotensin-aldosterone system. Treatment of normotensive cats with the combination products also revealed hypotensive effect, confirming earlier observation in SD rats.

Epinephrine administration caused a significant increase in the blood pressure of the anesthetized cat. Epinephrine acts on a presynaptic beta-receptor on sympathetic nerve 


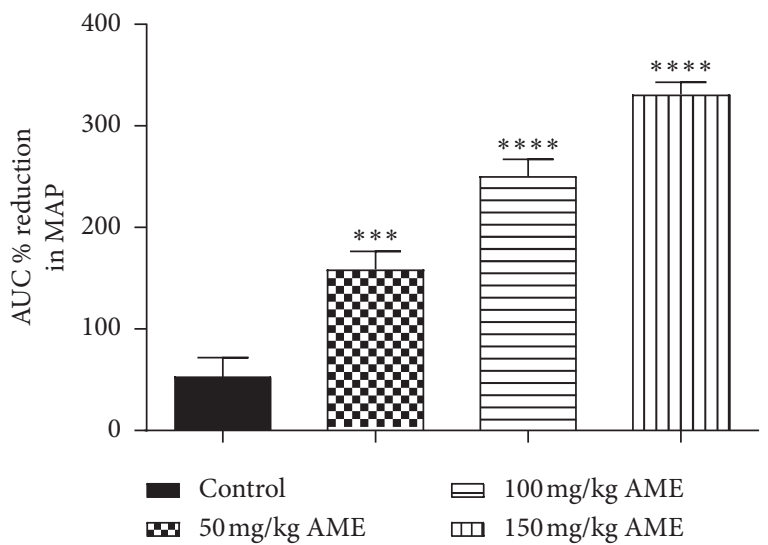

(a)

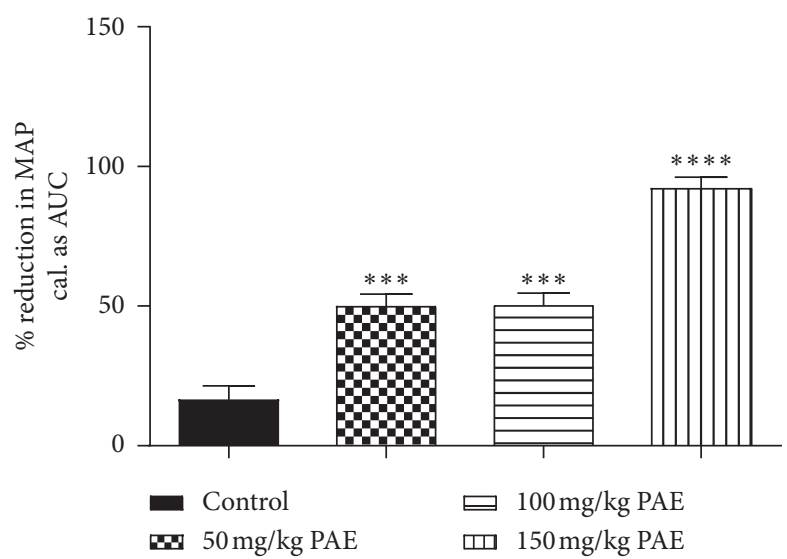

(b)

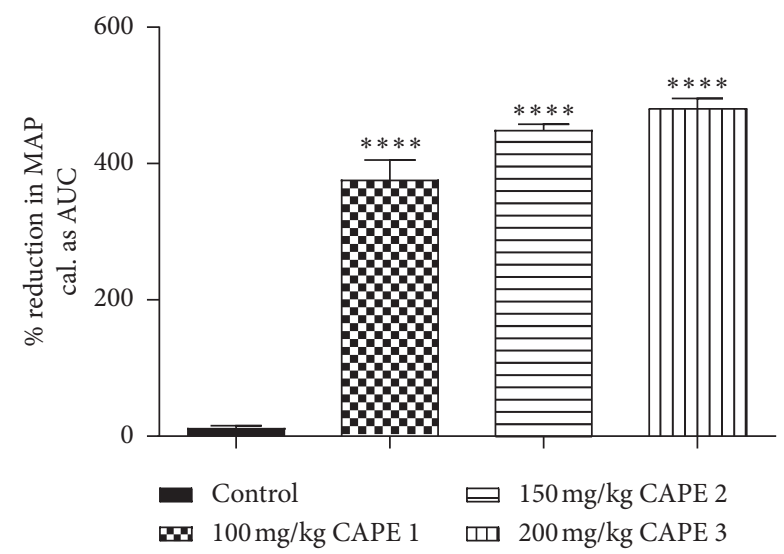

(c)

FIgURE 3: Percentage reduction in mean arterial pressure (MAP) caused by (a) AME, (b) PAE, and (c) CAPE administration to SD rats within 24 hours. Values are plotted as mean $\pm \operatorname{SEM}(n=6) .{ }^{* * *} p \leq 0.001$, compared to the control (one-way ANOVA with Dunnett's multiple comparison post hoc test). CAPE 1, CAPE 2, and CAPE 3 are combinations of AME and PAE in the ratios $1: 1,1: 2$, and $1: 3$, respectively.

TABLE 2: Effect of AME, PAE, and CAPE on the heart rate of normotensive rats.

\begin{tabular}{lccc}
\hline Time $(\mathrm{h})$ & $50 \mathrm{mg} / \mathrm{kg}$ & $100 \mathrm{mg} / \mathrm{kg}$ & $150 \mathrm{mg} / \mathrm{kg}$ \\
\hline$A M E$ & & & \\
0 & $400.17 \pm 8.40$ & $422.56 \pm 14.14$ & $432.67 \pm 20.00$ \\
4 & $408.61 \pm 12.71^{\mathrm{ns}}$ & $399.06 \pm 13.34^{\mathrm{ns}}$ & $400.78 \pm 13.58^{\mathrm{ns}}$ \\
8 & $408.39 \pm 65.88^{\mathrm{ns}}$ & $404.89 \pm 14.19^{\mathrm{ns}}$ & $410.67 \pm 8.67^{\mathrm{ns}}$ \\
24 & $410.39 \pm 18.00^{\mathrm{ns}}$ & $423.50 \pm 20.01^{\mathrm{ns}}$ & $403.78 \pm 7.72^{\mathrm{ns}}$ \\
\hline$P A E$ & & & \\
0 & $415.00 \pm 2.13$ & $415.00 \pm 2.13$ & $415.28 \pm 3.98$ \\
4 & $410.89 \pm 4.82^{\mathrm{ns}}$ & $415.56 \pm 6.26^{\mathrm{ns}}$ & $413.56 \pm 2.70^{\mathrm{ns}}$ \\
8 & $407.67 \pm 2.31^{\mathrm{ns}}$ & $406.11 \pm 3.16^{\mathrm{ns}}$ & $414.89 \pm 2.61^{\mathrm{ns}}$ \\
24 & $422.11 \pm 4.42^{\mathrm{ns}}$ & $439.33 \pm 22.46^{\mathrm{ns}}$ & $408.39 \pm 6.59^{\mathrm{ns}}$ \\
\hline$C A P E$ & $C A P E 1$ & $C A P E 2$ & $C A P E 3$ \\
0 & $424.44 \pm 9.22$ & $430.00 \pm 7.00$ & $418.78 \pm 9.85$ \\
4 & $346.66 \pm 5.33^{* * * *}$ & $339.00 \pm 1.73^{* * * *}$ & $41.89 \pm 3.11^{* * * *}$ \\
8 & $413.89 \pm 5.39^{\mathrm{ns}}$ & $416.33 \pm 11.18^{\mathrm{ns}}$ & $407.44 \pm 6.48^{\mathrm{ns}}$ \\
24 & $394.45 \pm 14.89^{\mathrm{ns}}$ & $423.89 \pm 10.39^{\mathrm{ns}}$ & $406.89 \pm 11.50^{\mathrm{ns}}$ \\
\hline
\end{tabular}

Values are recorded as mean $\pm \mathrm{SEM}, n=6$. Comparison of hours of treatment to the zero hour: ns: $p>0.05 ;{ }^{* * * *} p \leq 0.001$; one-way ANOVA followed by Dunnett's multiple comparisons test. 


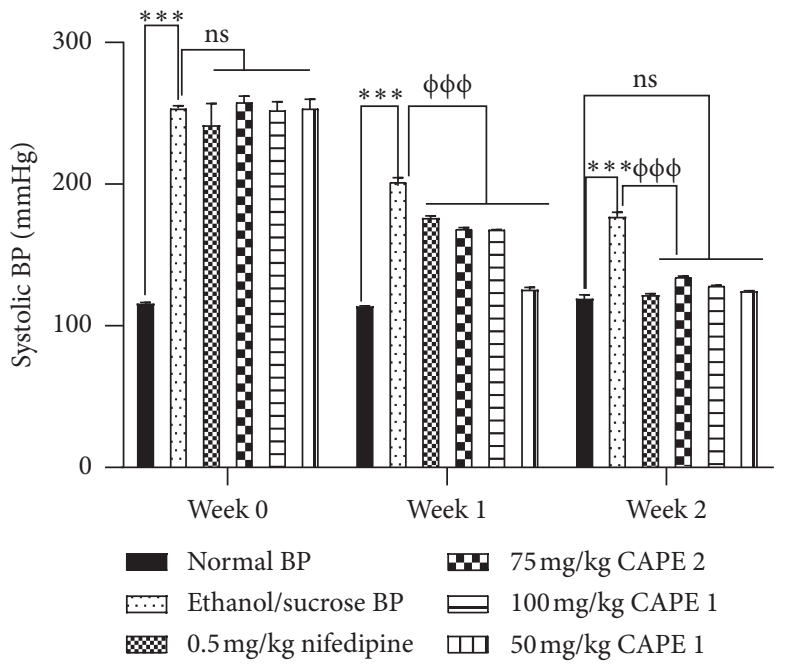

(a)

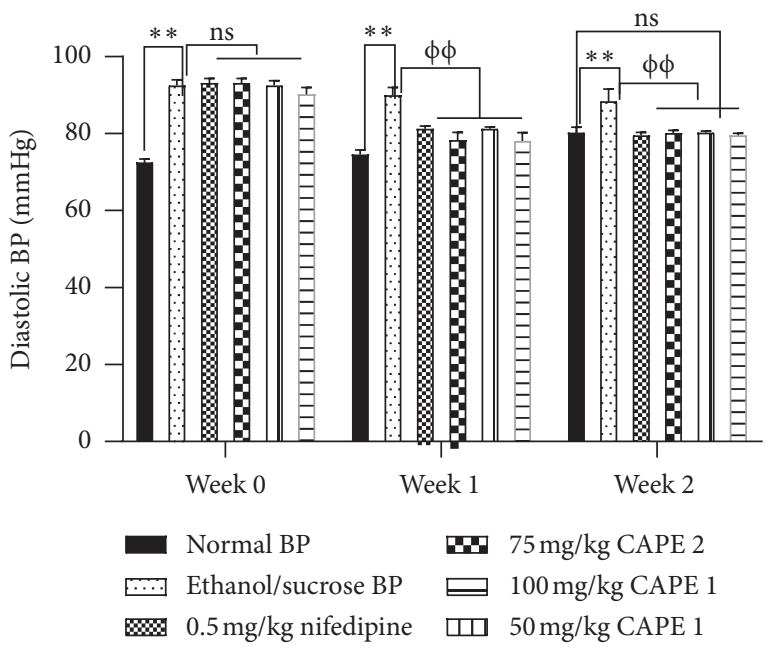

(b)

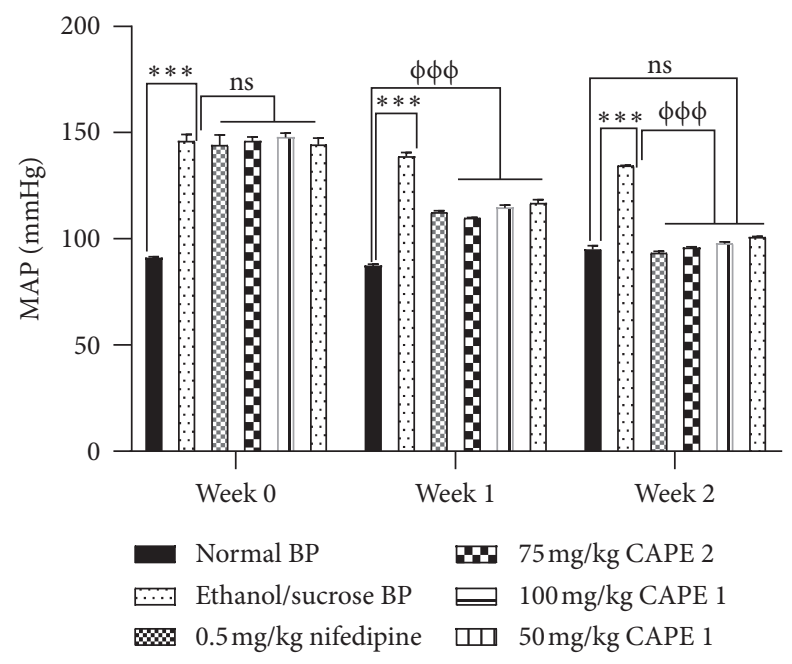

(c)

FIGURE 4: Effect of various concentrations of CAPE 1, CAPE 2, and nifedipine on (a) systolic blood pressure (SBP), (b) diastolic pressure (DBP), and (c) mean arterial pressure (MAP) in ethanol/sucrose-induced hypertension. Values are plotted as mean \pm SEM. ${ }^{* * *} p \leq 0.001$ compared to the normal control group and also ${ }^{\varphi \varphi \varphi} p \leq 0.001$ compared to the negative control group; one-way ANOVA with Dunnett's multiple comparison post hoc test.

endings which indirectly leads to a sustained increase in the neuronal release of norepinephrine [43]. Epinephrine-induced BP was significantly inhibited by all concentrations of CAPE 1 and CAPE 2, in a manner similar to that of nifedipine. Nifedipine reduces blood pressure by inhibiting the L-type voltage-sensitive calcium channels in vascular smooth muscles and myocardial cells [44]. The similar effect produced by the products and nifedipine may possibly suggest a calcium channel blocking mechanism on the myocardium and hence a reduction in force and rate of myocardial contraction (an effect noticed earlier in this study) [45].

Several research findings have revealed the presence of alkaloids, tannins, flavonoids, essential oils, and phenolic compounds in Annona muricata and Persea americana $[46,47]$ which could have contributed to their antihypertensive effect. For instance, Dias et al. [48] have reported that reticuline reduced blood pressure through voltage-dependent $\mathrm{Ca}^{2+}$ channel blockade and/or inhibition of $\mathrm{Ca}^{2+}$ release from norepinephrine-sensitive intracellular stores. Reticuline, an alkaloid, is one of the components of A. muricata leaves $[49,50]$. Also, some essential oils such as beta-caryophyllene present in other P. americana have been reported to exhibit hypotensive and vasodilator activities [51].

Complications in hypertension involve hematological, liver, and kidney disorders. Safety assessment of the combination products in hypertension management in experimental animals revealed no detrimental effect on hematological profile and liver and kidney function parameters. Urinalysis revealed the reversal of proteinuria caused by the induction of hypertension. Some herbal 


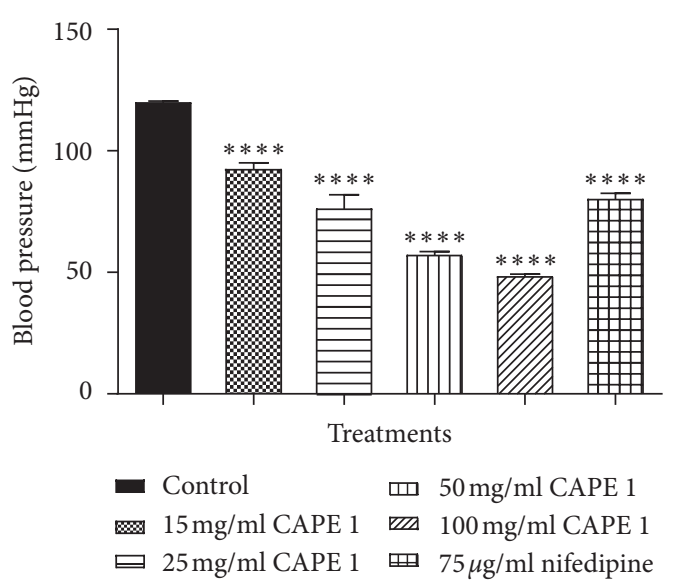

(a)

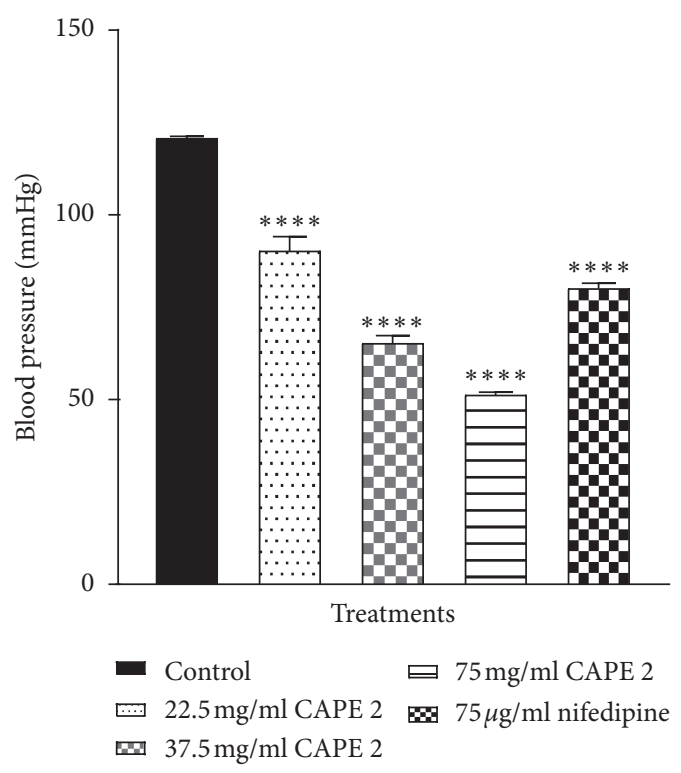

(c)

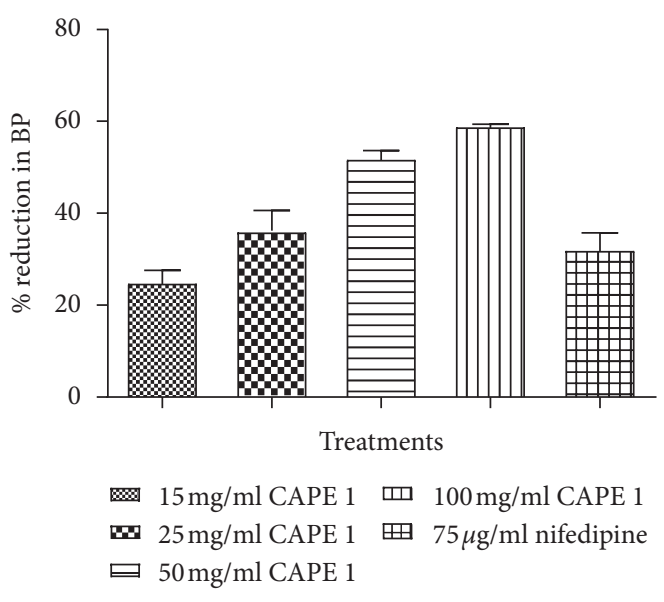

(b)

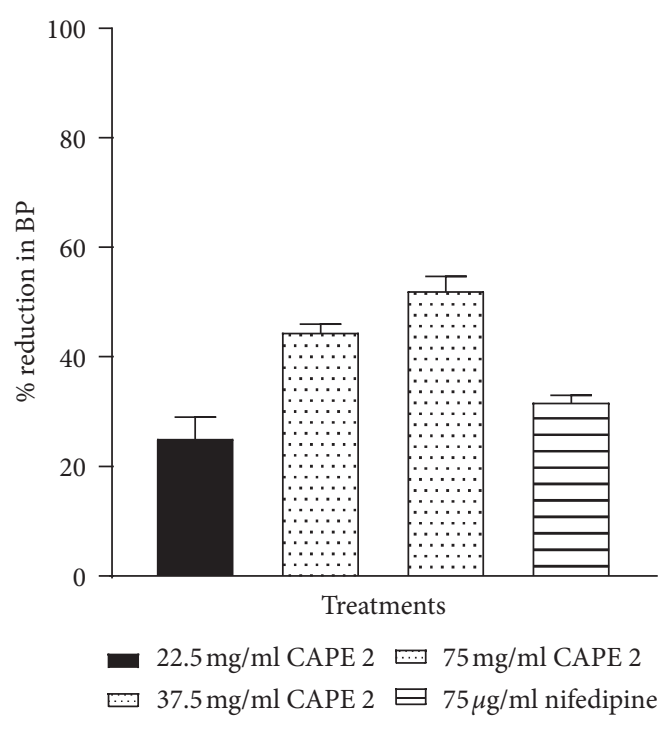

(d)

FIgUre 5: Effect of $(a, c)$ various concentrations of CAPE 1 and CAPE 2 on the blood pressure of normotensive cats, (b, d) showing percentage reduction in BP. Values are plotted as mean $+\operatorname{SEM}(n=3) .{ }^{*} p \leq 0.05,{ }^{* *} p \leq 0.01 ;{ }^{* * *} p \leq 0.001$ as compared to the control group; one-way ANOVA with Dunnett's multiple comparison post hoc test.

medicines can affect the osmotic fragility of blood cells causing cell lysis, resulting in decreased RBCs, haemoglobin, WBCs, PLTs which ends up with anemia, leucocytopenia, and thrombocytopenia [52]. These hematological disorders have several morbidity effects and could eventually result in mortality. Hemolysis of RBCs results in increased bilirubin levels in the blood causing cholestasis and jaundice, with eventual appearance in urine, as well as increased urobilinogen levels in the urine [53]. Others also decrease erythropoiesis resulting in decreased $\mathrm{RBC}$ levels and decreased haemoglobin levels [52]. The fact that the products have no effect on hematological profile implies that the product may not have affected hematopoiesis, and may not have hemolyzing tendencies, which augur well for therapeutic use.

Except for total bilirubin (TBIL) which was significantly reduced, liver function parameters were not affected by treatments. The liver is the main organ for drug metabolism and therefore prone to injury; the commonest enzymes employed as indicators of hepatocellular damage are the aminotransferase enzymes and alkaline phosphatase (ALP) [54]. Damage to the liver results in increased levels of these enzymes in the plasma and this is usually proportional to the extent of tissue damage [54]. The reduction of the total bilirubin on the administration of the product indicates a possible hepatoprotective effect [55] of CAPE which is preferred in hypertension management.

CAPE administration did not affect kidney function parameters, indicating that the product did not have any deleterious effect on kidney function. Elevated level of serum creatinine and urea would have indicated adverse effect on the kidneys [56].The "no adverse effect" on hematological profile, as well as on the liver and kidneys, was confirmed in the urinalysis results. Breakdown products in these organs/ 


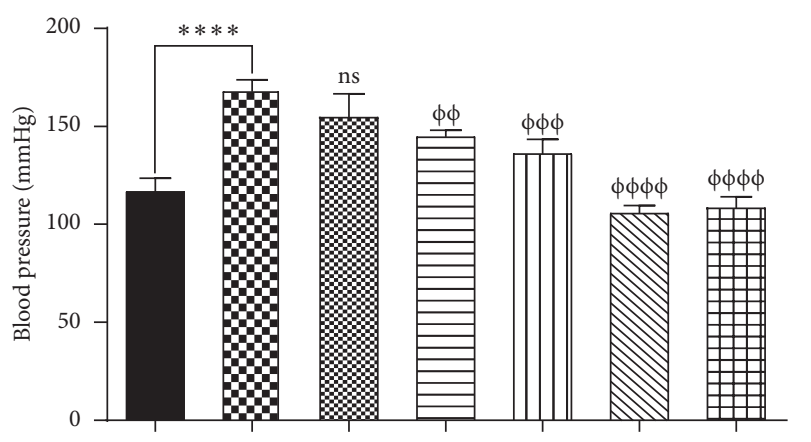

Treatments

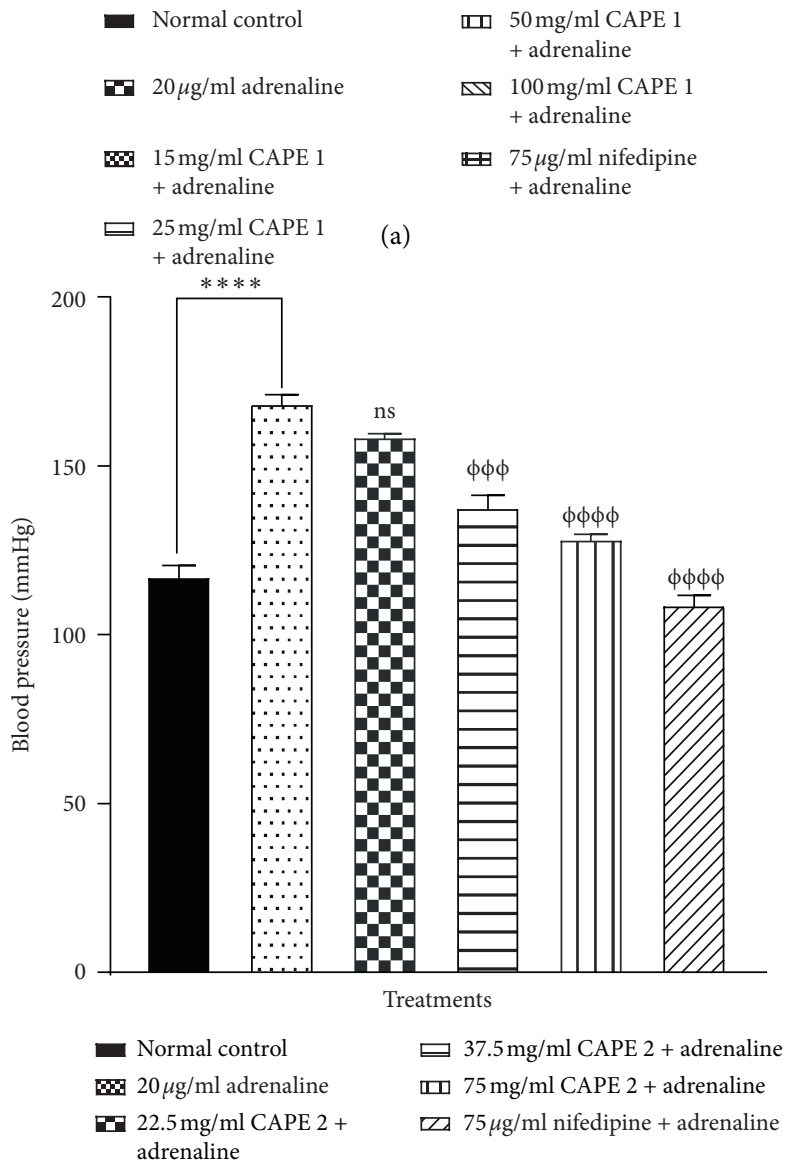

(c)

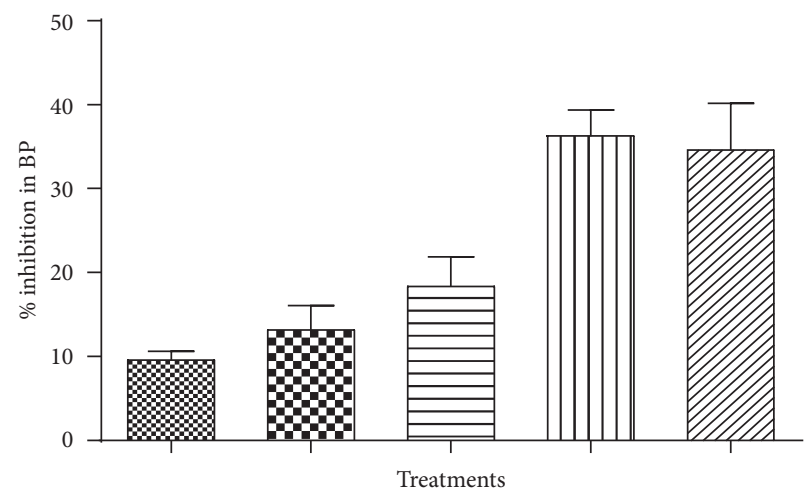
\$ $15 \mathrm{mg} / \mathrm{ml} \mathrm{CAPE} 1$ + adrenaline
$25 \mathrm{mg} / \mathrm{ml}$ CAPE 1
+ adrenaline
च $50 \mathrm{mg} / \mathrm{ml} \mathrm{CAPE} 1$
+ adrenaline

(b)
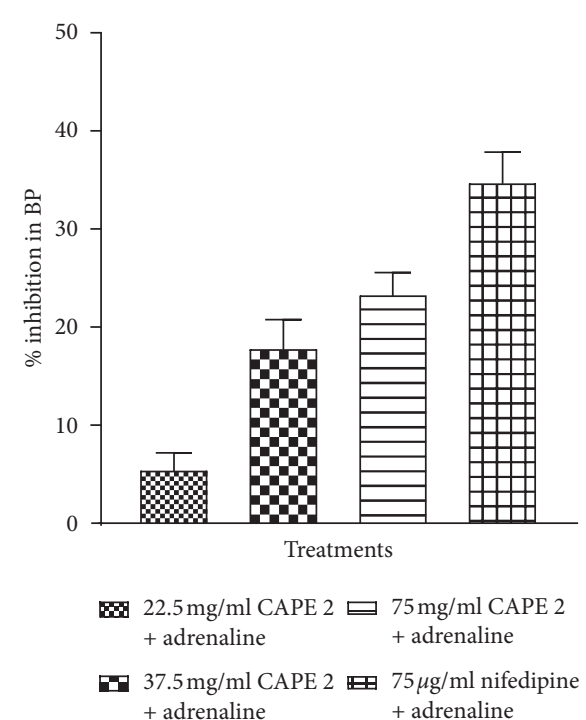

(d)

FIGURE 6: Effect of $(a, c)$ various concentrations of CAPE 1 and CAPE 2 on the blood pressure inhibition of epinephrine-induced hypertensive cats, $(\mathrm{b}, \mathrm{d})$ showing percentage inhibition of BP. Values are plotted as mean \pm SEM $(n=3)$. ${ }^{* * * *} p \leq 0.001$ as compared to the control group, ${ }^{\varphi \varphi \varphi} p \leq 0.01 ;{ }^{\varphi \varphi \varphi \varphi} p \leq 0.001$ as compared to the hypertensive control; one-way ANOVA with Dunnett's multiple comparison post hoc test.

systems will always be excreted into urine, hence the importance of performing urinalysis. Induction of hypertension resulted in elevated levels of protein in the urine (proteinuria)
[57]. This was however reversed after treatment with CAPE, confirming the antihypertensive property of the product and its safety for use in hypertension. 
TABle 3: Effect of 50, 75, and $100 \mathrm{mg} / \mathrm{kg}$ CAPE and nifedipine on full blood count.

\begin{tabular}{|c|c|c|c|c|c|c|}
\hline \multirow{2}{*}{ Parameter } & \multicolumn{3}{|c|}{ Combined extract $(\mathrm{mg} / \mathrm{kg})$} & \multirow{2}{*}{$0.5 \mathrm{mg} / \mathrm{kg}$ nifedipine } & \multirow{2}{*}{ Negative control } & \multirow{2}{*}{ Normal control } \\
\hline & 50 CAPE 1 & 75 CAPE 2 & 100 CAPE 1 & & & \\
\hline WBC $\left(\times 10^{3} / \mathrm{uL}\right)$ & $10.03 \pm 1.25$ & $9.08 \pm 0.51$ & $14.60 \pm 0.32$ & $11.48 \pm 1.36$ & $10.10 \pm 0.79$ & $12.60 \pm 0.20$ \\
\hline $\mathrm{RBC}\left(\times 10^{6} / \mathrm{uL}\right)$ & $8.16 \pm 0.30$ & $7.77 \pm 0.56$ & $8.01 \pm 0.14$ & $8.02 \pm 0.30$ & $8.16 \pm 0.17$ & $7.70 \pm 0.14$ \\
\hline $\mathrm{HGB}(\mathrm{g} / \mathrm{dL})$ & $14.73 \pm 0.86$ & $13.96 \pm 1.02$ & $14.14 \pm 0.17$ & $14.30 \pm 0.11$ & $14.35 \pm 0.16$ & $13.95 \pm 0.65$ \\
\hline HCT $(\%)$ & $45.03 \pm 1.48$ & $42.86 \pm 3.63$ & $44.66 \pm 1.28$ & $43.40 \pm 1.58$ & $44.98 \pm 0.41$ & $44.25 \pm 0.95$ \\
\hline MCV (fL) & $55.22 \pm 0.70$ & $54.96 \pm 1.14$ & $55.72 \pm 0.97$ & $54.15 \pm 0.59$ & $55.23 \pm 0.85$ & $57.50 \pm 0.20$ \\
\hline $\mathrm{MCH}(\mathrm{pg})$ & $18.02 \pm 0.53$ & $17.98 \pm 0.36$ & $17.68 \pm 0.26$ & $17.93 \pm 0.58$ & $17.63 \pm 0.48$ & $18.10 \pm 0.50$ \\
\hline $\mathrm{MCHC}(\mathrm{g} / \mathrm{dL})$ & $32.62 \pm 0.58$ & $32.74 \pm 0.51$ & $31.72 \pm 0.65$ & $33.08 \pm 1.05$ & $31.90 \pm 0.41$ & $31.50 \pm 0.80$ \\
\hline $\operatorname{PLT}\left(\times 10^{3} / \mathrm{uL}\right)$ & $614.17 \pm 90.97$ & $802.20 \pm 78.86$ & $668.00 \pm 77.60$ & $700.25 \pm 118.89$ & $693.50 \pm 92.47$ & $635.00 \pm 30.00$ \\
\hline LYM\% & $65.40 \pm 2.61$ & $69.74 \pm 3.01$ & $65.64 \pm 2.52$ & $67.05 \pm 1.88$ & $66.05 \pm 1.86$ & $69.50 \pm 0.30$ \\
\hline LYM\# $\left(\times 10^{3} / \mathrm{uL}\right)$ & $6.58 \pm 0.92$ & $6.30 \pm 0.39$ & $9.56 \pm 0.33$ & $7.75 \pm 1.12$ & $6.68 \pm 0.57$ & $8.75 \pm 0.05$ \\
\hline RDW_SD (fL) & $29.08 \pm 0.65$ & $26.56 \pm 3.39$ & $30.48 \pm 0.66$ & $30.70 \pm 1.19$ & $29.13 \pm 0.63$ & $29.70 \pm 1.40$ \\
\hline RDW_CV (\%) & $14.73 \pm 0.70$ & $13.10 \pm 0.97$ & $14.10 \pm 0.72$ & $16.03 \pm 1.95$ & $13.35 \pm 0.93$ & $12.50 \pm 1.00$ \\
\hline PDW (fL) & $10.17 \pm 0.20$ & $10.16 \pm 0.61$ & $10.40 \pm 0.74$ & $10.73 \pm 0.59$ & $9.78 \pm 0.09$ & $9.90 \pm 0.30$ \\
\hline MPV (fL) & $7.75 \pm 0.13$ & $8.90 \pm 0.93$ & $7.86 \pm 0.29$ & $7.63 \pm 0.17$ & $7.80 \pm 0.17$ & $7.65 \pm 0.05$ \\
\hline P_LCR (\%) & $11.77 \pm 0.76$ & $13.68 \pm 0.26$ & $13.24 \pm 1.73$ & $12.00 \pm 0.98$ & $12.10 \pm 0.90$ & $11.90 \pm 0.60$ \\
\hline
\end{tabular}

Values are expressed as mean $\pm \operatorname{SEM}(n=5)$. Statistical analysis indicated no significant difference $(p>0.05)$ (one-way ANOVA with Dunnett's post hoc test). WBC: white blood cell; RBC: red blood cell; HGB: haemoglobin; HCT: haematocrit; MCV: mean cell volume; MCH: mean cell haemoglobin; MCHC: mean cell haemoglobin concentration; PLT: platelet; LYM: lymphocyte; RDW: red cell distribution width; SD: standard deviation; CV: coefficient of variation; PDW: platelet distribution width; MPV: mean platelet volume; P_LCR: platelet large cell ratio.

TABLE 4: Effect of CAPE and nifedipine on liver and kidney function in ethanol/sucrose-induced hypertension in SD rats.

\begin{tabular}{|c|c|c|c|c|c|c|}
\hline \multirow{2}{*}{ Parameter } & \multicolumn{3}{|c|}{ Dose of combined product $(\mathrm{mg} / \mathrm{kg})$} & \multirow{2}{*}{ Nifedipine $(0.5 \mathrm{mg} / \mathrm{kg})$} & \multirow{2}{*}{ Negative control } & \multirow{2}{*}{ Normal control } \\
\hline & 50 CAPE 1 & 100 CAPE 1 & 75 CAPE 2 & & & \\
\hline $\operatorname{ALP}(\mathrm{U} / \mathrm{L})$ & $135.3 \pm 7.88$ & $152.9 \pm 11.09$ & $134.7 \pm 31.23$ & - & $149.5 \pm 24.82$ & $95.27 \pm 4.54$ \\
\hline Total protein $(\mathrm{g} / \mathrm{L})$ & $63.62 \pm 0.85$ & $67.44 \pm 1.13$ & $66.86 \pm 1.52$ & $71.65 \pm 1.55$ & $66.76 \pm 2.60$ & $69.30 \pm 0.80$ \\
\hline Albumen $(\mathrm{g} / \mathrm{L})$ & $31.80 \pm 0.84$ & $29.46 \pm 0.63$ & $32.28 \pm 1.21$ & $32.87 \pm 0.90$ & $31.38 \pm 1.34$ & $31.53 \pm 0.57$ \\
\hline $\operatorname{AST}(\mathrm{U} / \mathrm{L})$ & $158.9 \pm 14.58$ & $155.5 \pm 16.47$ & $145.3 \pm 10.54$ & $168.7 \pm 4.615$ & $148.5 \pm 15.45$ & $152.0 \pm 11.69$ \\
\hline $\operatorname{ALT}(\mathrm{U} / \mathrm{L})$ & $41.20 \pm 1.62$ & $41.33 \pm 2.40$ & $38.50 \pm 4.11$ & $31.75 \pm 1.63$ & $40.13 \pm 4.72$ & $31.17 \pm 2.69$ \\
\hline GGT (U/L) & $6.0 \pm 0.0$ & $6.0 \pm 0.0$ & $6.0 \pm 0.0$ & $6.0 \pm 0.0$ & $6.0 \pm 0.0$ & $6.0 \pm 0.0$ \\
\hline TBIL $(\mu \mathrm{mol} / \mathrm{L})$ & $3.94 \pm 0.25^{* * *}$ & $4.90 \pm 0.41^{* * *}$ & $4.54 \pm 0.22^{* * *}$ & $9.18 \pm 0.14$ & $9.74 \pm 0.39$ & $11.77 \pm 0.29$ \\
\hline Urea $(\mathrm{mmol} / \mathrm{L})$ & $6.91 \pm 0.58$ & $6.99 \pm 0.40$ & $7.08 \pm 0.47$ & - & $7.78 \pm 0.32$ & $8.54 \pm 0.33$ \\
\hline Creatinine $(\mu \mathrm{mol} / \mathrm{L})$ & $88.44 \pm 2.57$ & $88.13 \pm 2.77$ & $96.02 \pm 3.13$ & - & $83.84 \pm 3.77$ & $98.82 \pm 2.00$ \\
\hline $\mathrm{Na}(\mathrm{mmol} / \mathrm{L})$ & $143.6 \pm 0.39$ & $143.7 \pm 0.70$ & $144.4 \pm 0.55$ & $142.9 \pm 0.47$ & $143.3 \pm 1.07$ & $143.2 \pm 0.69$ \\
\hline $\mathrm{K}(\mathrm{mmol} / \mathrm{L})$ & $4.92 \pm 0.18$ & $5.43 \pm 0.07$ & $5.21 \pm 0.18$ & $5.86 \pm 0.29$ & $5.65 \pm 0.43$ & $5.72 \pm 0.14$ \\
\hline $\mathrm{Cl}(\mathrm{mmol} / \mathrm{L})$ & $102.9 \pm 0.64$ & $104.0 \pm 0.76$ & $105.1 \pm 0.76$ & $100.2 \pm 0.91$ & $102.4 \pm 0.39$ & $101.6 \pm 1.57$ \\
\hline
\end{tabular}

Values are expressed as mean $\pm \operatorname{SEM}(n=5){ }^{* * *} p \leq 0.001$ as compared to the normal control (one-way ANOVA with Dunnett's multiple comparison post hoc test). ALP: alkaline phosphatase; T: total; AST: aspartate aminotransferase; ALT: alanine aminotransferase; GGT- $\gamma$ : glutamyltransferase; Na sodium; K: potassium; Cl: chloride.

TABle 5: Effect of 50, 75, and $100 \mathrm{mg} / \mathrm{kg}$ CAPE and nifedipine on urine content in ethanol/sucrose-induced hypertension in SD rats.

\begin{tabular}{|c|c|c|c|c|c|c|}
\hline \multirow{2}{*}{ Parameter } & \multicolumn{3}{|c|}{ Combined extract $(\mathrm{mg} / \mathrm{kg})$} & \multirow{2}{*}{$0.5 \mathrm{mg} / \mathrm{kg}$ nifedipine } & \multirow{2}{*}{$\mathrm{HC}$} & \multirow{2}{*}{ NC } \\
\hline & 50 CAPE 1 & 75 CAPE 2 & 100 CAPE 1 & & & \\
\hline Leukocyte & Trace & Trace & Trace & Trace & Trace & Trace \\
\hline Urobilinogen & Trace & Trace & Trace & Trace & Trace & Trace \\
\hline Bilirubin & Negative & Negative & Negative & Negative & Negative & Negative \\
\hline Blood & Negative & Negative & Negative & Negative & Negative & Negative \\
\hline Nitrite & Negative & Negative & Negative & Negative & Negative & Negative \\
\hline $\mathrm{Ph}$ & $8.00 \pm 0.13$ & $8.50 \pm 0.00$ & $7.83 \pm 0.31$ & $7.58 \pm 0.30$ & $7.75 \pm 0.25$ & $7.13 \pm 0.13$ \\
\hline SG & $1.01 \pm 0.00$ & $1.01 \pm 0.00$ & $1.02 \pm 0.00$ & $1.02 \pm 0.00$ & $1.01 \pm 0.00$ & $1.08 \pm 0.06$ \\
\hline Protein & ++ & ++ & ++ & ++ & +++ & ++ \\
\hline Glucose & Negative & Negative & Negative & Negative & Negative & Negative \\
\hline Ketones & Negative & Negative & Negative & Negative & Negative & Negative \\
\hline
\end{tabular}

Values are expressed as mean \pm SEM $(n=5)$. SG: specific gravity; HC: negative control; NC: normal control. 


\section{Conclusion}

This study showed that aqueous extracts of Annona muricata, Persea americana, and their combination products have hypotensive and antihypertensive properties, with the combination products eliciting synergism on administration. The combination products are safe to use in hypertension, hence having a promising therapeutic advantage for prevention and treatment of hypertension in Ghana. It is recommended that chronic toxicity studies and possible mechanism of action of the combination products should further be studied and established.

\section{Data Availability}

All data generated or analysed during this study are included in this published article (and its supplementary information files). However, the datasets used and/or analysed during the current study are available from the corresponding author on reasonable request.

\section{Conflicts of Interest}

The authors declare that there are no conflicts of interest regarding the publication of this paper.

\section{Acknowledgments}

Special thanks go to Miss Judith, Abigail, Edwin Dery, Francis Ansah, Alex, and Prince Dagadu, for their guidance, technical support, data analysis, and provision of information, among others.

\section{References}

[1] World Health Organization (WHO), Cardiovascular Diseases (CVDs). (n.d.), World Health Organization (WHO), Geneva, Switzerland, 2017, https://www.who.int/news-room/factsheets/detail/cardiovascular-diseases-(cvds).

[2] C. R. D. Himmelfarb, Y. Commodore-mensah, and M. N. Hill, "Expanding the role of nurses to improve hypertension care and control globally," Annals of Global Health, vol. 82, no. 2, pp. 243-253, 2016.

[3] E. O'Brien, “The Lancet Commission on hypertension: addressing the global burden of raised blood pressure on current and future generations," Journal of Clinical Hypertension, vol. 19, no. 6, pp. 564-568, 2017.

[4] P. K. Mukherjee, Evidence-Based Validation of Herbal Medicines, Elsevier, Amsterdam, Netherlands, 2015.

[5] D. Pires de Lima, "Synthesis of angiotensin-converting enzyme (ACE) inhibitors: an important class of antihypertensive drugs Dênis Pires de Lima," Química Nova, vol. 22, no. 3, pp. 375-381, 1999.

[6] P. Kumar and L. M. Clark, Kumar and Clark's Clinical Medicine, Elsevier, Amsterdam, Netherlands, 2016.

[7] L. Herman and K. Bashir, Angiotensin Converting Enzyme Inhibitors, p. 2020, StatPearls Publishing, Treasure Island, FL, USA, 2018.

[8] B. M. Hicks, K. B. Filion, H. Yin, L. Sakr, J. A. Udell, and L. Azoulay, "Angiotensin converting enzyme inhibitors and risk of lung cancer: population based cohort study," BMJ (Clinical Research ed.), vol. 363, Article ID k4209, 2018.

[9] R. R. Dhungana, "Barriers to treatment and control of hypertension among hypertensive participants: a communitybased cross-sectional mixed method study in municipalities of Kathmandu, Nepal," Frontiers in Cardiovascular Medicine, vol. 3, p. 26, 2016.

[10] I. A. Kretchy, F. Owusu-daaku, and S. Danquah, "Patterns and determinants of the use of complementary and alternative medicine: a cross-sectional study of hypertensive patients in Ghana," BMC Complementary and Alternative Medicine, vol. 14, no. 1, pp. 1-7, 2014.

[11] I. Rifaat, M. Azmi, F. Saleem, H. F. Al, and O. Thanoon, "Use of complementary and alternative medicines: a cross-sectional study among hypertensive patients in Iraq," Journal of Pharmaceutical Health Service Research, vol. 9, no. 1, pp. 59-65, 2018.

[12] C. Siew-Mooi, R. Vasudevan, Z. A. Zakaria, and F. Paimin, "Frequency of complementary and alternative medicine usage among Malaysian hypertensive subjects," Life Science, vol. 10, no. 4, pp. 2226-2231, 2013.

[13] S. Parasuraman, G. Thing, and S. Dhanaraj, "Polyherbal formulation: concept of ayurveda," Pharmacognosy Reviews, vol. 8, no. 16, p. 73, 2014.

[14] S. Mallat, B. Y. Tanios, and H. S. Itani, "Current perspectives on combination therapy in the management of hypertension," Integrated Blood Pressure Control, vol. 6, pp. 69-78, 2013.

[15] J. A. Tayade, A. V. Patil, G. O. Alade, T. O. Alade, and O. R. Omobuwajo, "Phytochemistry \& natural products," Anti-Fertility Activity of Bambusa Vulgaris Aqueous Leaf Extract in Male Wistar Rats, vol. 3, no. 6, p. 6836, 2015.

[16] G. Kendir and A. Köroğlu, "Evaluation of avocado (Persea americana mill.) leaves in terms of public health," Marmara Pharmaceutical Journal, vol. 22, no. 3, pp. 347-356, 2018.

[17] G. Komlaga and S. Cojean, "The antimalarial potential of three Ghanaian medicinal plants," Herbal Medicine: Open Access, vol. 1, no. 1, p. 4, 2016.

[18] J. D. Abraham, J. Abraham, and J. F. Takrama, "Morphological characteristics of avocado (Persea americana Mill.) in Ghana," African Journal of Plant Science, vol. 12, no. 4, pp. 88-97, 2018.

[19] J. A. O. Ojewole, D. R. Kamadyaapa, M. M. Gondwe, K. Moodley, and C. T. Musabayane, "Cardiovascular topics cardiovascular effects of Persea americana mill (Lauraceae) (avocado) aqueous leaf extract in experimental animals," Cardiovascular Journal of South Africa, vol. 18, no. 2, pp. 69-76, 2007.

[20] M. A. Owolabi, H. A. B. Coker, and S. I. Jaja, "Bioactivity of the phytoconstituents of the leaves of Persea americana," Journal of Medicinal Plants Research, vol. 4, no. 12, pp. 1130-1135, 2010.

[21] A. V. Coria-Téllez, E. Montalvo-Gónzalez, E. M. Yahia, and E. N. Obledo-Vázquez, "Annona muricata: a comprehensive review on its traditional medicinal uses, phytochemicals, pharmacological activities, mechanisms of action and toxicity," Arabian Journal of Chemistry, vol. 11, no. 5, pp. 662-691, 2015.

[22] S. Patel, J. K. Patel, and C. Sejal Patel, "A review on a miracle fruits of Annona muricata," Journal of Pharmacognosy and Phytochemistry, vol. 5, no. 51, pp. 137-148, 2016.

[23] M. H. Burkill, "Annona muricata in global plants on JSTOR," 1985, https://plants.jstor.org/compilation/annona.muricata? searchUri=.

[24] C. R. Nwokocha, D. U. Owu, A. Gordon et al., "Possible mechanisms of action of the hypotensive effect of Annona 
muricata (soursop) in normotensive Sprague-Dawley rats," Pharmaceutical Biology, vol. 50, no. 11, pp. 1436-1441, 2012.

[25] T.-C. Chou, "Drug combination studies and their synergy quantification using the Chou-Talalay method," Cancer Research, vol. 70, no. 2, pp. 440-446, 2010.

[26] S. Vasdev, I. P. Gupta, C. Sampson, L. Longerich, and S. Parai, "Ethanol induced hypertension in rats: reversibility and role of intracellular cytosolic calcium," Artery, vol. 20, no. 1, pp. 19-43, 1993.

[27] P. D. D. Dzeufiet, A. Mogueo, D. C. Bilanda et al., "Antihypertensive potential of the aqueous extract which combine leaf of Persea americana Mill. (Lauraceae), stems and leaf of Cymbopogon citratus (D.C) Stapf. (Poaceae), fruits of Citrus medical L. (Rutaceae) as well as honey in ethanol and sucrose experi," BMC Complementary and Alternative Medicine, vol. 14, no. 1, pp. 1-12, 2014.

[28] K. I. Melville, "Blood-pressure effects of norEpinephrine and Epinephrine with special reference to their antagonism by ergotoxine and other blocking agents," Journal of Physiology, vol. 113, no. 1910, pp. 346-364, 1951.

[29] J. K. Sarma, G. C. Bhuyan, J. Koley, L. Mainty, and V. Naikwadi, "An experimental evaluation of the effect of rudraksha (Elaeocarpus ganitrus roxb) in epinephrine and nicotine induced hypertension," Ancient Science, vol. 23, no. 4, pp. 1-10, 2004.

[30] W. Zou, Y. Yang, Y. Gu et al., "Repeated blood collection from tail vein of non-anesthetized rats with a vacuum blood collection system," Journal of Visualized Experiments, vol. 130, no. 130, Article ID e55852, 2017.

[31] C. Brown, "Blood collection from the tail of a rat," Lab Animal, vol. 35, no. 8, pp. 24-25, 2006.

[32] N. Tabassum and F. Ahmad, "Role of natural herbs in the treatment of hypertension," Pharmacognosy Reviews, vol. 5, no. 9, pp. 30-40, 2011.

[33] A. Siddiqui, "Effects of vasodilation and arterial resistance on cardiac output," Journal of Clinical and Experimental Cardiology, vol. 2, no. 11, 2010.

[34] S. Goineau, P. Lacroix, and P. Soares-da-Silva, "Influence of enalapril therapy schedule on the progression of the disease in dilated cardiomyopathic Syrian hamsters (bio TO-2 strain)," Journal of Clinical \& Experimental Cardiology, vol. 1, no. 1, pp. 102-105, 2010.

[35] H. M. Vetulli, M. V. Elizari, G. V. Naccarelli, and M. D. Gonzalez, "Cardiac automaticity: basic concepts and clinical observations," Journal of Interventional Cardiac Electrophysiology, vol. 52, no. 3, pp. 263-270, 2018.

[36] R. De Ponti, J. Marazzato, G. Bagliani, F. M. Leonelli, and L. Padeletti, "Sick sinus syndrome," Cardiac Electrophysiology Clinics, vol. 10, no. 2, pp. 183-195, 2018.

[37] P. L. K. Tennakoon, "Studies on plant growth promoting rhizomicroorganisms of tea (Camellia Sinensis (L.) Kuntze) plants," Master's thesis, University of Agriculture Sciences, Dharwad (Institute), Karnataka, India, 2007.

[38] S. Tsuji, S. Kawano, T. Michida et al., "Ethanol stimulates immunoreactive endothelin-1 and -2 release from cultured human umbilical vein endothelial cells," Alcoholism: Clinical and Experimental Research, vol. 16, no. 2, pp. 347-349, 1992.

[39] L. B. Moreira, F. D. Fuchs, R. S. Moraes, M. Bredemeier, and B. B. Duncan, "Alcohol intake and blood pressure," Journal of Hypertension, vol. 16, no. 2, pp. 175-180, 1998.

[40] K. Husain, M. Vazquez, R. A. Ansari, M. P. Malafa, and J. Lalla, "Chronic alcohol-induced oxidative endothelial injury relates to angiotensin II levels in the rat," Molecular and Cellular Biochemistry, vol. 307, no. 1-2, pp. 51-58, 2008.
[41] J. W. Wright, S. L. Morseth, R. H. Abhold, and J. W. Harding, "Elevations in plasma angiotensin II with prolonged ethanol treatment in rats," Pharmacology Biochemistry and Behavior, vol. 24, no. 4, pp. 813-818, 1986.

[42] H. Rupp, C. G. Brilla, and B. Maisch, "Hypertension and alcohol: central and peripheral mechanisms," Herz, vol. 21, pp. 258-264, 1996.

[43] M. J. Brown and C. T. Dollery, "Adrenaline and hypertension," Clinical and Experimental Hypertension. Part A: Theory and Practice, vol. 6, no. 1-2, pp. 539-549, 1984.

[44] E. M. Sorkin, S. P. Clissold, and R. N. Brogden Nifedipine, "Nifedipine a review of its pharmacodynamic and pharmacokinetic properties, and therapeutic efficacy, in ischaemic heart disease, hypertension and related cardiovascular disorders," Drugs, vol. 30, no. 3, pp. 182-274, 1985.

[45] R. I. Low, P. Takeda, D. T. Mason, and A. N. DeMaria, “The effects of calcium channel blocking agents on cardiovascular function," The American Journal of Cardiology, vol. 49, no. 3, pp. 547-553, 1982.

[46] S. Park, Y. H. Nam, I. Rodriguez et al., "Chemical constituents of leaves of Persea americana (avocado) and their protective effects against neomycin-induced hair cell damage," Revista Brasileira de Farmacognosia, vol. 29, no. 6, pp. 739-743, 2019.

[47] M. J. Rieser, J. F. Kozlowski, K. V. Wood, and J. L. McLaughlin, "Muricatacin: a simple biologically active acetogenin derivative from the seeds of annona muricata (annonaceae)," Tetrahedron Letters, vol. 32, no. 9, pp. 1137-1140, 1991.

[48] K. L. Dias, C. Da Silva Dias, J. M. Barbosa-Filho, R. N. Almeida, N. De Azevedo Correia, and I. A. Medeiros, "Cardiovascular effects induced by reticuline in normotensive rats," Planta Medica, vol. 70, no. 4, pp. 328-333, 2004.

[49] M. Leboeuf, C. Legueut, A. Cavé, J. Desconclois, P. Forgacs, and H. Jacquemin, "Alcaloïdes des Annonacées XXIX: alcaloïdes de l'Annona muricata L," Planta Medica, vol. 42, no. 5, pp. 37-44, 1981.

[50] M. Leboeuf, A. Cavé, P. K. Bhaumik, B. Mukherjee, and R. Mukherjee, "The phytochemistry of the Annonaceae," Phytochemistry, vol. 21, pp. 2783-2813, 1982.

[51] C. E. N. Damiani, C. M. Moreira, H. T. Zhang, T. L. Creazzo, and D. V. Vassallo, "Effects of eugenol, an essential oil, on the mechanical and electrical activities of cardiac muscle," Journal of Cardiovascular Pharmacology, vol. 44, no. 6, pp. 688-695, 2004.

[52] O. J. Sule, I. Elekwa, and E. O. Ayalogu, "Effect of Acalypha wilkesiana muell Arg. on haematological parameters in wistar albino rats," International Journal of Biological and Medical Research, vol. 3, no. 1, pp. 1234-1237, 2012.

[53] W. Barcellini and B. Fattizzo, "Clinical applications of hemolytic markers in the differential diagnosis and management of hemolytic anemia," Disease Markers, vol. 2015, Article ID 635670, 7 pages, 2015.

[54] E. G. Giannini, R. Testa, and V. Savarino, "Liver enzyme alteration: a guide for clinicians," Canadian Medical Association Journal, vol. 172, no. 3, pp. 367-379, 2005.

[55] K. C. Anantha, R. C. Siva, and R. A. Manohar, "Hepatoprotective effect of biherbal ethanolic extract against paracetamol-induced hepatic damage in albino rats," Journal of Ayurveda and Integrative Medicine, vol. 3, no. 4, pp. 198-203, 2012.

[56] N. M. Paige and G. T. Nagami, "The top 10 things nephrologists wish every primary care physician knew," Mayo Clinic Proceedings, vol. 84, no. 2, pp. 180-186, 2009.

[57] A. Yates, "Urinalysis: how to interpret results: nursing times online, issue 2(1-3)," 2016, https://www.nursingtimes.net/ clinical-archive/continence/urinalysis-how-to-interpret-resul ts/7005353.article-07-06-2016/Accessed:2020-10-16. 